\title{
Cisternostomy in Traumatic Brain Injury for a Novel Approach to Treatment: Review of Current Status
}

\author{
Manish Agrawal ${ }^{1}$ Keshav Mishra ${ }^{1, \odot}$ Rohit Babal ${ }^{1}$ Devendra Purohit ${ }^{1}$ \\ ${ }^{1}$ Department of Neurosurgery, SMS Medical College and Hospital, \\ Address for correspondence Keshav Mishra, MS, \\ Jaipur, Rajasthan, India \\ Department of Neurosurgery, SMS Medical College and \\ Hospital, Jaipur, Rajasthan, India \\ (e-mail: dr.keshav666@gmail.com).
}

Indian J Neurotrauma 2022;19:34-39.

\begin{abstract}
Keywords

- cisternostomy

- traumatic brain injury

- CSF shift edema

- Virchow-Robin spaces

Cisternostomy (CS) is a recently introduced procedure to mitigate the cerebrospinal fluid shift edema and secondary injury in traumatic brain injury patients. There have been numerous reports describing its efficacy in various cohorts of traumatic brain injury (TBI) patients; therefore, we review the current evidences examining its utility for the same. The systematic review was done according to Preferred Reporting Items for Systematic Reviews and Meta-Analyses guideline including all human studies published in English language indexed with MEDLINE and Google Scholar since 2013 evaluating CS as a standalone or as an adjuvant procedure. The studies were graded according to the Oxford center for evidence-based medicine levels of evidence. Case reports were excluded from the analysis. A total of 107 articles were found by using the given search criteria. Finally, three oxford level 3 study and one level 4 study were included in the analysis. CS in combination with decompressive craniectomy was seen to confer mortality benefit and better outcome at discharge. It led to statistically significant improvement in clinical outcome at 6 months in the patients for whom it was performed as a primary procedure. CS is a promising procedure in TBI leading to survival benefit as well as better clinical outcome. But the level of evidence supporting its effectiveness is still weak owing to the methodological limitations and small sample size. A well-designed multicentric randomized controlled trial is needed to critically examine its role in TBI patients.
\end{abstract}

\section{Introduction}

Traumatic brain injury (TBI) is a critical public health problem worldwide constituting a major cause of mortality and morbidity for people of all ages, but especially in the young age group. With the recent increase in its incidence, injury-related deaths and TBI are projected to be one of the major causes of death and disability by the year $2020 .{ }^{1}$ The principle of TBI management centers on the prevention and mitigation of secondary brain injury. However, the progress in its management has not paralleled the progress seen in

published online April 8, 2021
DOI https://doi.org/

10.1055/s-0041-1726224 ISSN 0973-0508. other neurosurgical disciplines. The major advances in care of TBI patients have been attributed to the development and evolution of intensive care and neurophysiological monitoring. Initially described by Theodore Kocher, decompressive craniectomy has recently been shown to improve the patient survival while increasing the neurological morbidity. ${ }^{2,3}$

Originally described by Cherian et al, cisternostomy (CS) has recently been proposed as an effective procedure for TBI management. ${ }^{4}$ It has been shown to be effective both as standalone as well as adjunctive procedure to decompressive craniectomy. CS is defined by opening and drainage of

\footnotetext{
(C) 2021. Neurotrauma Society of India.
}

This is an open access article published by Thieme under the terms of the Creative Commons Attribution-NonDerivative-NonCommercial-License, permitting copying and reproduction so long as the original work is given appropriate credit. Contents may not be used for commercial purposes, or adapted, remixed, transformed or built upon. (https://creativecommons.org/licenses/by-nc-nd/4.0/).

Thieme Medical and Scientific Publishers Pvt. Ltd. A-12, 2nd Floor, Sector 2, Noida-201301 UP, India 
subarachnoid basal cistern to atmospheric pressure. The procedure is based on the principle of opening subarachanoidal cisterns leading to opening of paravascular Virchow-Robin spaces resulting in changes in CSF circulation, consequently reducing the CSF shift edema. ${ }^{5}$

Even though an innovative procedure based on a renewed understanding of the pathophysiology of TBI, the evidence supporting the viability and efficacy of procedure is sparse at present. We therefore aim to systematically examine the rationale and effectiveness of CS in TBI population.

\section{Materials and Methods}

The systematic review has been done in accordance with the PRISMA guideline (-Table $\mathbf{1}$ ). Human studies published in English language after 2013 (since the conception of the procedure) addressing the role of CS alone or as adjuvant to decompressive craniectomy in patients with traumatic brain injury, describing the patient characteristics and outcome were sought. PubMed, MEDLINE, EMBASE, and google scholar search was done from 2013 to 2020, limited to articles published in English language using keywords "CS" (including related keywords like "cisternotomy") together with traumatic brain injury, TBI, brain injury, and head injury. Non-English language and nonhuman studies were excluded from the analysis. The references of the included articles were searched for potential publications. The studies were evaluated for the TBI patient population, severity of injury, the relevant control group and the procedure performed in each, and postoperative outcomes and complications if any. The outcome was compared with respect to reduction in intracranial pressure (ICP), mortality benefit, improved outcome at 6 weeks or 6 months. The articles included were categorized according to the Oxford Center for Evidence Based Medicine levels of evidence. ${ }^{6}$

Table 1 Preferred Reporting Items for Systematic Reviews and Meta-Analyses checklist

\begin{tabular}{|c|c|c|c|}
\hline Section/topic & & Checklist item & $\begin{array}{l}\text { Reported on } \\
\text { page }\end{array}$ \\
\hline \multicolumn{4}{|l|}{ Title } \\
\hline Title & 1 & Identify the report as a systematic review, meta-analysis, or both & 3 \\
\hline \multicolumn{4}{|l|}{ Abstract } \\
\hline Structured summary & 2 & $\begin{array}{l}\text { Provide a structured summary including as applicable: background; objectives; } \\
\text { data sources; study eligibility criteria, participants, and interventions; study } \\
\text { appraisal and synthesis methods; results; limitations; conclusions and implica- } \\
\text { tions of key findings; systematic review registration number }\end{array}$ & 1 \\
\hline \multicolumn{4}{|l|}{ Introduction } \\
\hline Rationale & 3 & Describe the rationale for the review in the context of what is already known & 2 \\
\hline Objectives & 4 & $\begin{array}{l}\text { Provide an explicit statement of questions being addressed with reference to } \\
\text { participants, interventions, comparisons, outcomes, and study design (PICOS) }\end{array}$ & 2 \\
\hline \multicolumn{4}{|l|}{ Methods } \\
\hline Protocol and registration & 5 & $\begin{array}{l}\text { Indicate if a review protocol exists, if and where it can be accessed (e.g., Web } \\
\text { address), and, if available, provide registration information including registra- } \\
\text { tion number }\end{array}$ & no \\
\hline Eligibility criteria & 6 & $\begin{array}{l}\text { Specify study characteristics (e.g., PICOS, length of follow-up) and report char- } \\
\text { acteristics (e.g., years considered, language, publication status) used as criteria } \\
\text { for eligibility, giving rationale }\end{array}$ & 3 \\
\hline Information sources & 7 & $\begin{array}{l}\text { Describe all information sources (e.g., databases with dates of coverage, con- } \\
\text { tact with study authors to identify additional studies) in the search and date } \\
\text { last searched }\end{array}$ & 3 \\
\hline Search & 8 & $\begin{array}{l}\text { Present full electronic search strategy for at least one database, including any } \\
\text { limits used, such that it could be repeated }\end{array}$ & 3 \\
\hline Study selection & 9 & $\begin{array}{l}\text { State the process for selecting studies (i.e., screening, eligibility, included in } \\
\text { systematic review, and, if applicable, included in the meta-analysis) }\end{array}$ & 3 \\
\hline Data collection process & 10 & $\begin{array}{l}\text { Describe method of data extraction from reports (e.g., piloted forms, inde- } \\
\text { pendently, in duplicate) and any processes for obtaining and confirming data } \\
\text { from investigators }\end{array}$ & 3 \\
\hline Data items & 11 & $\begin{array}{l}\text { List and define all variables for which data were sought (e.g., PICOS, funding } \\
\text { sources) and any assumptions and simplifications made }\end{array}$ & \\
\hline
\end{tabular}


Table 1 (Continued)

\begin{tabular}{|c|c|c|c|}
\hline Section/topic & & Checklist item & $\begin{array}{l}\text { Reported on } \\
\text { page }\end{array}$ \\
\hline $\begin{array}{l}\text { Risk of bias in individual } \\
\text { studies }\end{array}$ & 12 & $\begin{array}{l}\text { Describe methods used for assessing risk of bias of individual studies (including } \\
\text { specification of whether this was done at the study or outcome level), and how } \\
\text { this information is to be used in any data synthesis }\end{array}$ & 3 \\
\hline Summary measures & 13 & State the principal summary measures (e.g., risk ratio, difference in means) & \\
\hline Synthesis of results & 14 & $\begin{array}{l}\text { Describe the methods of handling data and combining results of studies, if } \\
\text { done, including measures of consistency }\left(\text { e.g., }\left.\right|^{2}\right) \text { for each meta-analysis }\end{array}$ & \\
\hline Risk of bias across studies & 15 & $\begin{array}{l}\text { Specify any assessment of risk of bias that may affect the cumulative evidence } \\
\text { (e.g., publication bias, selective reporting within studies) }\end{array}$ & $4-6$ \\
\hline Additional analyses & 16 & $\begin{array}{l}\text { Describe methods of additional analyses (e.g., sensitivity or subgroup analyses, } \\
\text { meta-regression), if done, indicating which were pre-specified }\end{array}$ & \\
\hline \multicolumn{4}{|l|}{ Results } \\
\hline Study selection & 17 & $\begin{array}{l}\text { Give numbers of studies screened, assessed for eligibility, and included in the } \\
\text { review, with reasons for exclusions at each stage, ideally with a flow diagram }\end{array}$ & 3 \\
\hline Study characteristics & 18 & $\begin{array}{l}\text { For each study, present characteristics for which data were extracted (e.g., } \\
\text { study size, PICOS, follow-up period) and provide the citations }\end{array}$ & 3 \\
\hline Risk of bias within studies & 19 & $\begin{array}{l}\text { Present data on risk of bias of each study and, if available, any outcome level } \\
\text { assessment (see item 12) }\end{array}$ & \\
\hline $\begin{array}{l}\text { Results of individual } \\
\text { studies }\end{array}$ & 20 & $\begin{array}{l}\text { For all outcomes considered (benefits or harms), present, for each study: (a) } \\
\text { simple summary data for each intervention group (b) effect estimates and } \\
\text { confidence intervals, ideally with a forest plot }\end{array}$ & Table 1 \\
\hline Synthesis of results & 21 & $\begin{array}{l}\text { Present results of each meta-analysis done, including confidence intervals and } \\
\text { measures of consistency }\end{array}$ & \\
\hline Risk of bias across studies & 22 & Present results of any assessment of risk of bias across studies (see item 15) & \\
\hline Additional analysis & 23 & $\begin{array}{l}\text { Give results of additional analyses, if done (e.g., sensitivity or subgroup analy- } \\
\text { ses, meta-regression [see item 16]) }\end{array}$ & \\
\hline \multicolumn{4}{|l|}{ Discussion } \\
\hline Summary of evidence & 24 & $\begin{array}{l}\text { Summarize the main findings including the strength of evidence for each main } \\
\text { outcome; consider their relevance to key groups (e.g., healthcare providers, } \\
\text { users, and policy makers) }\end{array}$ & $4-6$ \\
\hline Limitations & 25 & $\begin{array}{l}\text { Discuss limitations at study and outcome level (e.g., risk of bias), and at } \\
\text { review-level (e.g., incomplete retrieval of identified research, reporting bias) }\end{array}$ & 6 \\
\hline Conclusions & 26 & $\begin{array}{l}\text { Provide a general interpretation of the results in the context of other evidence, } \\
\text { and implications for future research }\end{array}$ & 6 \\
\hline \multicolumn{4}{|l|}{ Funding } \\
\hline Funding & 27 & $\begin{array}{l}\text { Describe sources of funding for the systematic review and other support (e.g., } \\
\text { supply of data); role of funders for the systematic review }\end{array}$ & \\
\hline
\end{tabular}

Abbreviation: PICOS, Patients, Intervention, Comparison, and Outcome.

\section{Results}

A brief summary of the search result and the study selection process is shown in - Fig. 1. Overall, 107 studies were identified based on the initial search of the database included published between 2013 and 2020. Duplicate studies, case reports, letter to editor, and personal communications and those deemed irrelevant after title and abstract evaluation were removed. Finally, four articles were included in the review process.
The study characteristics and the classification of studies according to the strength of evidence is summarized in - Table 2. Overall, three oxford level 3 study and one level 4 study were identified. There was one prospective nonrandomized controlled trial, two retrospective cohort studies, and one case series exploring the role of CS in severe TBI patients. Two studies compared effect of adjuvant CS to DC with DC alone. One study compared DC with and without adjuvant CS with CS as the only procedure. One case series evaluated the effectiveness of CS as the standalone procedure. 


\section{Discussion}

Traumatic brain injury can potentially be a grave condition which could be a source of severe morbidity and potentially life threatening. The evolution of TBI depends on the severity of primary injury, which is dependent on the energy transfer to the intracranial structures during the impact as well as secondary brain injury resulting from consecutive injury processes initiated due to the primary damage leading to continued injury and delayed presentation. Secondary injury includes the development of cerebral edema, elevated

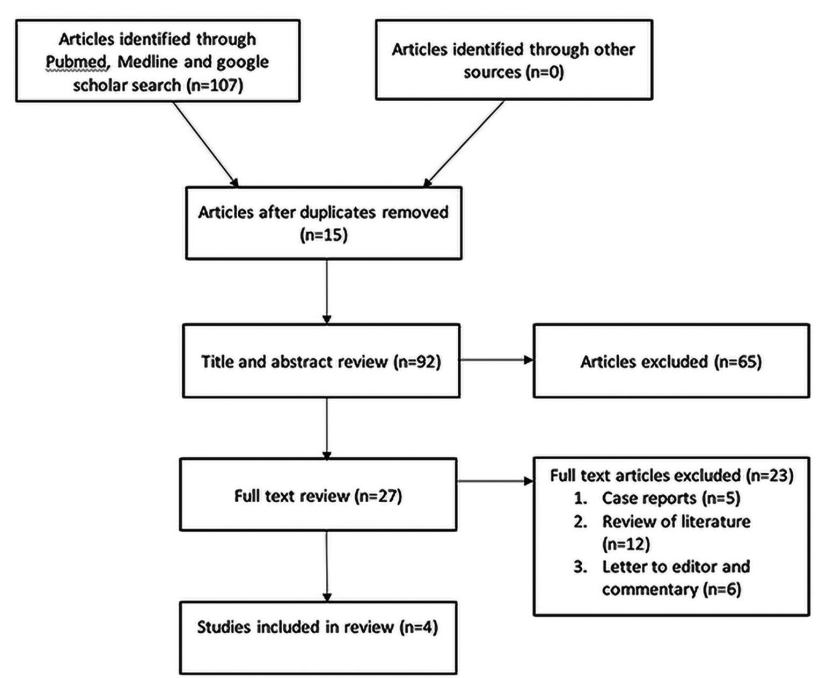

Fig. 1 Result of study selection with Preferred Reporting Items for Systematic Reviews and Meta-Analyses flow diagram.
ICP, and brain ischemia. The development of post-traumatic cerebral edema has diverse but incompletely understood mechanism. However, the current understanding suggests that cytotoxic edema is the first to develop at the site of injury, which creates a gradient for subsequent trans-capillary movement of fluid resulting in vasogenic edema. ${ }^{7}$ The change in the capillary permeability ensues due to ischemic processes, which along with the build-up of starling forces is necessary for the development of edema process. It is a sequential process which starts with endothelial dysfunction also known as ionic edema progressing to the breakdown of blood-brain barrier eventually, leading to complete disruption of capillary integrity leading to hemorrhagic conversion. ${ }^{7}$ However, recent development pioneered by Iliff et $\mathrm{al}^{8}$ demonstrating the importance of glymphatic system in cerebrospinal fluid (CSF) flow from subarachnoid space through the peri-vascular Virchow-Robin spaces into the brain parenchyma paved the way for improved understanding of the pathophysiology of brain injury. The glymphatic clearance of CSF and solutes was found to decrease by as much as $60 \%$ following an episode of TBI. ${ }^{9}$ Therefore, as a consequence of either decreased clearance of interstitial fluid from brain parenchyma or increased CSF influx into parenchyma via peri-vascular spaces there is yet another potential pathway for development and evolution of brain edema postinjury, also known as "CSF-shift edema." The hypothesis concerning "CSF-shift edema" was verified experimentally in a pilot study by Goyal et al, where they found a pressure gradient between the measured cisternal and parenchymal pressures in TBI patients undergoing DC and CS. They demonstrated that immediately following CS,

Table 2 Characteristics of studies included in the review

\begin{tabular}{|c|c|c|c|c|c|c|}
\hline S. no. & Article & Authors & Study design & $\begin{array}{l}\text { Level of } \\
\text { evidence }\end{array}$ & $\begin{array}{l}\text { Number of } \\
\text { patients }\end{array}$ & Outcome \\
\hline 1. & $\begin{array}{l}\text { Cisternostomy: replacing } \\
\text { the age old decompressive } \\
\text { hemicraniectomy? }^{4}\end{array}$ & $\begin{array}{l}\text { lype Cherian } \\
\text { Ghuo Yi } \\
\text { Sunil } \\
\text { Munakomi }\end{array}$ & $\begin{array}{l}\text { Prospective } \\
\text { nonrandomized } \\
\text { controlled study } \\
\text { (single person } \\
\text { triple center) }\end{array}$ & 3 & $\begin{array}{l}D C=284 \\
D C+C S=272 \\
C T=476\end{array}$ & $\begin{array}{l}\text { Mortality } \\
D C=34.8 \% \\
D C+C S=26.4 \% \\
C S=15.6 \% \\
\text { GOS at } 6 \mathrm{wk} \\
D C=2.8 \\
D C+C S=3.7 \\
C S=3.9\end{array}$ \\
\hline 2. & $\begin{array}{l}\text { Role of cisternal drainage in } \\
\text { patients with traumatic brain } \\
\text { injury undergoing decom- } \\
\text { pressive craniectomy }{ }^{14}\end{array}$ & $\begin{array}{l}\text { Amit Thapa } \\
\text { Rupendra } \\
\text { Bahadur } \\
\text { Adhikari } \\
\text { Bidur KC } \\
\text { Bikram Shakya }\end{array}$ & $\begin{array}{l}\text { Retrospective } \\
\text { cohort study } \\
\text { (double center) }\end{array}$ & 3 & $\begin{array}{l}D C=73 \\
D C+C S=77\end{array}$ & $\begin{array}{l}\text { Mortality rate }(p=0.052) \\
D C+C S=28.6 \% \\
D C=43.8 \% \\
\text { COS at } 6 \text { months }(p=0.323) \\
D C+C S=3.4 \\
D C=3.03\end{array}$ \\
\hline 3. & $\begin{array}{l}\text { Outcomes of severe head } \\
\text { injury patients undergoing } \\
\text { cisternostomy at tertiary } \\
\text { care hospital in Nepal }\end{array}$ & $\begin{array}{l}\text { lype Cherian } \\
\text { Hira Burhan }\end{array}$ & $\begin{array}{l}\text { Retrospective } \\
\text { case series }\end{array}$ & 4 & $C S=50$ & $\begin{array}{l}\text { Mortality rate }=10 \% \\
\text { Good outcome at } \\
2 \text { months }=76 \%\end{array}$ \\
\hline 4. & $\begin{array}{l}\text { Implementation of } \\
\text { cisternostomy as adjuvant } \\
\text { to decompressive } \\
\text { craniectomy for the } \\
\text { management of severe } \\
\text { brain trauma }{ }^{15}\end{array}$ & $\begin{array}{l}\text { Lorenzo } \\
\text { Giammattei } \\
\text { Daniele } \\
\text { Starnoni } \\
\text { Rodolfo Maduri }\end{array}$ & $\begin{array}{l}\text { Retrospective } \\
\text { cohort study }\end{array}$ & 3 & $\begin{array}{l}D C=22 \\
D C+C S=18\end{array}$ & $\begin{array}{l}\text { Mortality rate } \\
D C=27 \% \\
D C+C S=22 \% \\
\text { GOS }>5 \text { at } 6 \text { mo } \\
D C=35 \% \\
D C+C S=61.1 \%\end{array}$ \\
\hline
\end{tabular}

Abbreviations: CS, cisternostomy; CT, computed tomography; DC, decompressive craniectomy; GOS, Glasgow outcome scale. 
cisternal pressure was lower than parenchymal pressure and the maintenance of the pressure gradient was associated with clinical improvement whereas rise in cisternal and parenchymal pressure and reversal of the gradient correlated with poor clinical outcome. ${ }^{12}$

CS as a surgical procedure in the setting of TBI was introduced for the first time in 2013 by Cherian et al. ${ }^{4}$ The principle of the procedure lies in drainage of CSF from basal cisterns, thereby equalizing the cisternal pressure to atmospheric level causing reversal of the pressure gradient created between cisterna and brain parenchyma, preventing the CSF shift edema and consequent rise in ICP. ${ }^{13}$ The classical surgical procedure in TBI, that is, decompressive craniectomy provides increased volume for the edematous brain to expand, but this novel procedure by influencing the basic mechanism of edema formation aims to limit the secondary injury. Even though this is an exciting development based on better understanding of the pathophysiology of the disease process, it would be prudent to examine the evidences examining its utility in TBI population.

The first prospective study evaluating CS in different cohorts of TBI patients was reported by Cherian et al. ${ }^{4}$ The author described his 6-year experience in his series on 1,032 patients overall, divided into three groups according to the procedure performed: decompressive craniectomy (DC) alone $(n=284), \mathrm{DC}+\mathrm{CS}(n=272)$, and CS alone $(n=476)$. The population undergoing CS was heterogeneous consisting of $9.3 \%$ mild injury and $39.2 \%$ severe head injury. The outcome was described in terms of mortality in severe head injury group (34.8\% for DC, $26.4 \%$ for DC + CS, $15.6 \%$ for CS alone), days on ventilator ( $C S=2.4, D C+C S=3.2$, and $\mathrm{DC}=6.3$ ), and GOS at 6 weeks $(\mathrm{DC}=2.8, \mathrm{DC}+\mathrm{CS}=3.7$, and $\mathrm{CS}=3.9$ ). CS was seen to confer a mortality advantage both in combination with DHC and as a standalone procedure compared with patient undergoing DHC alone. The patients in CS group also had decreased ventilatory requirement and higher mean GOS score at 6 weeks. However, there were several limitations in the study methodology and results. The demography and severity of injury in the study population as well as among the subgroup has not been commented upon. The methodology is also sparse on the management protocol being followed in head injury including the use of ICP monitoring and antiedema measures. The indications for carrying out surgical management and the rationale influencing the decision to opt for a particular surgical procedure is not clearly mentioned. Importantly, the intraoperative findings like severe brain edema, hematoma in peri-sylvian region, etc., which could impair the optimal visualization and opening of cisterns as well as their influence on the feasibility of procedure performed and intraoperative complications were not described. The postoperative complications and outcome stratified to the severity of injury were not adequately stated. The follow-up duration of 6 weeks also seem to be suboptimal for determining any definitive outcome for the study population. Even though it was a triple center study, all the procedures were performed by a single surgeon.
Thapa et al performed retrospective study comparing TBI patients who underwent DC $(n=73)$ with DC + CS $(n=77) .{ }^{14}$ The two groups were evenly matched except in terms of age (38.5 years in DC group vs. 31.7 years in $\mathrm{DC}+\mathrm{CS}$ group $p=0.016)$ and GCS at presentation $(p=0.034)$. The procedure could be completed successfully in all the cases and it took an additional surgical time of 10 minutes. Death rate was $28.6 \%$ in DC + CS group compared with $43.8 \%$ in DC only group ( $p=0.052)$ amounting to absolute risk reduction of $15.2 \%$ for DC + CS group. However, at 6-month follow-up, the mean GOS score between the two groups was not statistically significant ( $\mathrm{DC}=3.03 \mathrm{vs}$. $\mathrm{DC}+\mathrm{CS}=3.4, p=0.323$ ). As the groups were not evenly matched in terms of severity of injury (mean GCS at presentation) and mean age of patients, the demonstrated treatment effect could have been affected.

Giammattei et al performed a retrospective study in severe TBI patients comparing DC $(n=22)$ with DC + CS $(n=18) \cdot{ }^{15}$ The groups were comparable with respect to age and GCS at presentation, but the DC + CS group had more patients with unilateral pupillary dilation (55 vs. 36\%) and higher average Rotterdam CT score ( 4.7 vs. 3.8; $p=0.03$ ). The decision to add CS to DC was based on the availability of surgeon skilled in vascular and skull base approaches, which can be a source of introducing selection bias. CS was successfully performed in all the 18 cases with slightly longer average operating time (204 vs. 178 minutes). Although the mortality rates were similar in both the groups (22 vs. $27 \%$ ), the CS group had reduced mechanical ventilation duration, ICU stay, and also better GCS scores at the time of discharge $(p=0.001)$. At 6 months of follow-up, those patients in DC + CS group had more favorable clinical outcome (GOS $\geq$ 5; 61.1 vs. $35 \%$; $p=0.1$ ). Moreover, the patients in whom CS was performed as a primary procedure had better clinical outcome scores at 6 -month follow-up ( $p=0.01$ ). However, the favorable results obtained in this study cannot be generalized because of retrospective nature of the study, limited number of patients and selection bias in choice of surgical procedure. $^{13}$

Cherian and Burhan published yet another series exploring the role of CS as a standalone procedure in severe TBI patients. ${ }^{16}$ They recruited 50 severe TBI cases over 9 months duration. The patients with age more than 80 years and motor score of 2 and less were excluded, but those with bilaterally dilated pupil were included in the study. All the patient successfully underwent CS and bone flap was replaced in 48 out of 50 cases. The average cisternal drain pressure on first postoperative day was $9.3 \mathrm{~mm} \mathrm{H}_{2} \mathrm{O}$ which decreased to $7.0 \mathrm{~mm}$ $\mathrm{H}_{2} \mathrm{O}$ on day 5. At 2-month follow-up, good recovery was seen in $76 \%$ cases, severe disability in 6 and $10 \%$ patients had died. Even though the results are promising, but the study lacks a control group.

\section{Conclusion}

Combined with DC has been shown to have favorable effect on mortality, duration of ventilator requirement and ICU stay, better GCS scores at discharge, and better clinical 
outcome; CS as the standalone procedure has been shown to reduce cisternal pressure, along with conferring mortality benefit, reducing ventilator duration and ICU stay. The studies exploring this procedure have been limited by either sample size or study design even though the results have been promising but they need thorough and rigorous evaluation before it can be considered as standard of care either in adjuvant or standalone setting, therefore a well-designed multicentric randomized controlled trial is needed to critically examine utility and viability of the procedure in TBI patients.

\section{Funding}

None.

\section{Conflict of Interest}

None declared.

\section{References}

1 Mathers CD, Loncar D. Projections of global mortality and burden of disease from 2002 to 2030. PLoS Med 2006;3(11):e442

2 Rossini Z, Nicolosi F, Kolias AG, Hutchinson PJ, De Sanctis P, Servadei F. The history of decompressive craniectomy in traumatic brain injury. Front Neurol 2019;10:458

3 Hutchinson PJ, Kolias AG, Timofeev IS, et al; RESCUEicp Trial Collaborators. Trial of decompressive craniectomy for traumatic intracranial hypertension. $N$ Engl J Med 2016;375(12):1119-1130

4 Cherian I, Yi G, Munakomi S. Cisternostomy: replacing the age old decompressive hemicraniectomy? Asian J Neurosurg 2013;8(3):132-138

5 Cherian I, Beltran M, Landi A, Alafaci C, Torregrossa F, Grasso G. Introducing the concept of "CSF-shift edema" in traumatic brain injury. J Neurosci Res 2018;96(4):744-752
6 Group OLoEW. The Oxford levels of evidence 2. 2011. Available at: www.cebm.net/index.aspx?o=5653. Accessed June 20, 2020

7 Simard JM, Kent TA, Chen M, Tarasov KV, Gerzanich V. Brain oedema in focal ischaemia: molecular pathophysiology and theoretical implications. Lancet Neurol 2007;6(3):258-268

8 Iliff JJ, Wang M, Liao Y, et al. A paravascular pathway facilitates CSF flow through the brain parenchyma and the clearance of interstitial solutes, including amyloid $\beta$. Sci Transl Med 2012;4(147):147ra111-147ra11

9 Iliff JJ, Chen MJ, Plog BA, et al. Impairment of glymphatic pathway function promotes tau pathology after traumatic brain injury. J Neurosci 2014;34(49):16180-16193

10 Yang L, Kress BT, Weber HJ, et al. Evaluating glymphatic pathway function utilizing clinically relevant intrathecal infusion of CSF tracer. J Transl Med 2013;11(1):107

11 Bothwell SW, Janigro D, Patabendige A. Cerebrospinal fluid dynamics and intracranial pressure elevation in neurological diseases. Fluids Barriers CNS 2019;16(1):9

12 Goyal N, Kumar P. Putting 'CSF-shift' edema hypothesis to test: Comparing cisternal and parenchymal pressures after basal cisternostomy for head injury. World Neurosurg 2021;S1878-8750(20):32700-32705

13 Goyal N, Kumar P, Chaturvedi J, Siddiqui SA, Agrawal D. Basal cisternostomy in traumatic brain injury: an idea whose time has come? Indian Journal of Neurotrauma. 2020;17(01):03-5

14 Thapa A, Adhikari RB, Bidur KC, Shakya B. Role of cisternal drainage in patients with traumatic brain injury undergoing decompressive craniectomy. Nepal Journal of Neuroscience 2018;15(3):14-20

15 Giammattei L, Starnoni D, Maduri R, et al. Implementation of cisternostomy as adjuvant to decompressive craniectomy for the management of severe brain trauma. Acta Neurochir (Wien) 2020;162(3):469-479

16 Cherian I, Burhan H. Outcomes of severe head injury patients undergoing Cisternostomy from a tertiary care hospital in Nepal. Indonesian Journal of Neurosurgery 2019;2(3) 